\title{
Ação social, matéria-prima da Sociologia
}

\author{
Social action, raw material of Sociology \\ Acción social, materia prima de la Sociología
}

Recebido: 01/05/2021 | Revisado: 05/09/2021 | Aceito: 23/10/2021 | Publicado: 24/10/2021

\author{
Adelcio Machado dos Santos ${ }^{1}$ \\ ORCID https://orcid.org/0000-0003-3916-972X \\ Universidade do Alto Vale do Rio do Peixe, Brasil \\ E-mail: adelciomachado@gmail.com \\ Rubens Luís Freiberger ${ }^{2}$ \\ ORCID https://orcid.org/0000-0002-1520-1580 \\ Universidade do Alto Vale do Rio do Peixe \\ E-mail: rubens.freiberger@gmail.com \\ Dreone Mendes ${ }^{3}$ \\ ORCID https://orcid.org/0000-0002-6150-0450 \\ Universidade do Alto Vale do Rio do Peixe \\ E-mail: dreone@gmail.com
}

\begin{abstract}
Resumo
Os indivíduos habitam as sociedades é nesse ambiente que ocorre a ação social, quando o indivíduo estabelece uma relação significativa, ou seja, quando tenta estabelecer algum tipo de comunicação durante a realização de uma ação social com outro(s) indivíduo(s). A ação social acontece entre individuo(s) quando diz respeito sobre o comportamento de outros e orienta-se por este(s) para o seu desenvolvimento. (Weber, 1921). A Sociologia vai mais além do que o simples estudo das condições de existência social dos seres humanos. (Fernandes, 1960). Pesquisa qualitativa, explanatória, a partir de uma revisão bibliográfica na medida em que busca explicar a ação social produzida em sociedade como matéria-prima do estudo da Sociologia. A ciência busca entender as interações sociais, desenvolvidas durante as ações sociais, nos mais diversos tipos de agrupamentos humanos. A manutenção da sociedade precisa ser conservada com uma moral coletiva, na divisão social do trabalho, solidariedade orgânica gerida por tradições, hábitos, valores e códigos morais que orientem a vida dos indivíduos em sociedade. Conclui-se que socialização guia e organiza o desenvolvimento do homem em concordância com os objetivos que a sociedade persegue.
\end{abstract}

Palavras-chave: Sociologia; Ação social; Construto estratégico.

\begin{abstract}
Individuals inhabit societies and it is in this environment that social action occurs, when the individual establishes a meaningful relationship, that is, when he/she tries to establish some type of communication while performing a social action with other individual(s). Social action takes place between individual(s) when it concerns the behavior of others and is guided by them for its development. (Weber, 1921). Sociology goes beyond the simple study of the conditions of social existence of human beings. (Fernandes, 1960). Qualitative, explanatory research, based on a literature review insofar as it seeks to explain the social action produced in society as the raw material for the study of Sociology. The science seeks to understand social interactions, developed during social actions, in the most diverse types of human groupings. The maintenance of society needs to be preserved with a collective moral, in the social division of labor, organic solidarity managed by traditions, habits, values and moral codes that guide the life of individuals in society. It is concluded that socialization guides and organizes the development of man in accordance with the goals society pursues.
\end{abstract}

Keywords: Sociology; Social action; Strategic construct.

\section{Resumen}

Los individuos habitan en sociedades y es en este entorno donde se produce la acción social, cuando el individuo establece una relación significativa, es decir, cuando intenta establecer algún tipo de comunicación durante la realización de una acción social con otro(s) individuo(s). La acción social se da entre individuo(s) cuando se trata del comportamiento de otros y es guiada por ellos para su desarrollo. (Weber, 1921). La sociología va más allá del simple estudio de las condiciones de existencia social de los seres humanos. (Fernandes, 1960). Investigación cualitativa,

\footnotetext{
${ }^{1}$ Doutor em Engenharia e Gestão do Conhecimento pela Universidade Federal de Santa Catarina (UFSC). Pós-Doutor em Gestão do Conhecimento pela UFSC. Universidade do Alto Vale do Rio do Peixe (UNIARP).

${ }^{2}$ Mestrando do Programa de Pós-Graduação em Desenvolvimento e Sociedade da UNIARP. UNIARP.

${ }^{3}$ Mestrando do Programa de Pós-Graduação "Stricto Sensu" em Sociedade e Desenvolvimento da UNIARP. UNIARP.
} 
explicativa, basada en una revisión bibliográfica en la medida en que busca explicar la acción social producida en la sociedad como materia prima del estudio de la Sociología. La ciencia busca comprender las interacciones sociales, desarrolladas durante las acciones sociales, en los más diversos tipos de agrupaciones humanas. El mantenimiento de la sociedad necesita ser preservado con una moral colectiva, en la división social del trabajo, la solidaridad orgánica gestionada por tradiciones, hábitos, valores y códigos morales que guían la vida de los individuos en la sociedad. Se concluye que la socialización orienta y organiza el desarrollo del hombre de acuerdo con los objetivos que la sociedad persigue.

Palabras clave: Sociología; Acción social; Construcción estratégica.

\section{Introdução}

Em uma sociedade a ação social acontece quando o indivíduo estabelece uma relação significativa, ou seja, quando tenta estabelecer algum tipo de comunicação durante a realização de uma ação social com outro(s) indivíduo(s). Nem toda ação realizada entre os indivíduos pode ser considerada uma ação social, será social, mas apenas aquelas que impliquem alguma orientação significativa visando outros indivíduos (Tomazil, 1993).

A ação tem sentido quando planejada e executada, se a ação acontece sem essa sequência de passos e sem a participação do outro, a ação é social. Lembrando que a ação social difere para cada um dos envolvidos no seu movimento, para aquele que a executa, para aquele que interage e para aquele que observa (Garcez, 2014).

O pensamento sociológico de Weber inicia-se a partir das relações sociais dos indivíduos com o meio social, para o sociólogo a sociedade baseia-se na concepção da ação social e a sociologia é a ciência que a compreende e a estuda (Silva \& Amorim, 2012).

Para o Sociólogo Emile Durkheim, a sociedade é um conjunto de normas de ação, pensamento e sentimento, que prevalece sobre o indivíduo. Não existe apenas nas consciências dos indivíduos, mas que são construídas exteriormente, fora das consciências individuais. Sem esse conjunto as sociedades não existem e os indivíduos não seriam obrigados a obedecê-las (Lucena, 2010).

Vila Nova (1981), de forma peculiar, orienta que a definição de Sociologia como "ciência da sociedade", pressupõe que se saiba o que é sociedade e, por conseguinte, se posta diante de uma espécie de círculo vicioso: a Sociologia se define como "ciência" da sociedade, e a sociedade têm de ser definida pela Sociologia. Portanto, é mais prudente afirmar que a Sociologia é uma ciência.

Assim sendo, Sell (2001) corrobora esta definição, acrescentando que a Sociologia é uma forma de saber científico originado no século XIX. Como qualquer ciência, ela não é fruto do mero acaso, mas responde às necessidades dos homens de seu tempo.

Por conseguinte, segundo o autor, a Sociologia tem também as suas causas históricas e sociais. Compreender o contexto no qual a Sociologia nasceu é fator fundamental para se entender as suas características atuais e a ação social.

\section{Metodologia}

O presente estudo caracteriza-se por uma pesquisa qualitativa, explanatória na medida em que busca explicar a ação social como matéria-prima do estudo da Sociologia. Buscou-se a utilização de um estudo bibliográfico com o objetivo da aproximação com os termos ação social; matéria prima; sociologia.

A pesquisa qualitativa, segundo Denzin e Lincolm (2006), procura interpretar o mundo e aqueles que o habitam, na sociologia a busca é entender os fenômenos sociais a partir da interpretação que as pessoas conferem de mundo.

O levantamento de artigos ocorreu principalmente em periódicos da sociologia brasileira, no acervo digital on-line Scientific Eletronic Library Online (SciELO). A SciELO é uma plataforma eletrônica internacional, que abriga uma coleção de periódicos científicos que abordam as mais diversas áreas. 
A pesquisa bibliográfica parte do levantamento de publicações divulgadas por escrito e / ou eletronicamente. O pesquisador busca com a pesquisa recolher o maior número de informações e referências teóricas publicadas a respeito do que se procuram respostas (Gil, 2007).

Selecionou-se, através da pesquisa na SciELO, os periódicos relevantes para responder o problema de pesquisa, entre eles destacamos: Civitas - Revista Ciências Sociais (Porto Alegre), Revista Administração de Empresas (São Paulo), Caderno CRH (Salvador), Tempo Social (São Paulo), Sociedade e Estado (Brasília), Revista Katálysis (Florianópolis), Revista de Administração Pública (Rio de Janeiro), Revista Brasileira de Educação (Rio de Janeiro), Revista Brasileira de Ciências Sociais (São Paulo), Psicologia em Estudo (Maringá), Educação e Pesquisa (São Paulo), Revista Eletrônica Arma da Crítica (Fortaleza) e Caderno de Pesquisa (São Paulo).

Totalizando 15 (quinze) artigos encontrados na íntegra, que após leitura exaustiva foram selecionados e analisados. Cronologicamente, os artigos foram incluídos os publicados no Brasil entre 1993 e 2018. O "ápice" das publicações foi entre 2010, 2012, 2013, 2014 e 2016. O ano e 2016, encontrou-se o maior número de publicações, com 2 (dois) artigos no mesmo periódico. Não foram encontrados artigos publicados em duplicidade na base de dados.

Também, criaram-se os tipos ideias, que são resultados de uma reflexão baseada nas informações desses estudos. Descrevem, de forma geral, valores, interesses e percepções da sociedade, servem como referência na análise interpretativa com a bibliografia encontrada.

\section{Desenvolvimento}

Constitui truísmo que a reflexão sobre os fenômenos sociais não encetou com a Sociologia, no século XIX, conforme enfatiza Vila Nova (1981).

Em consonância com este o autor, antes que Auguste Comte inventasse na primeira metade daquele século a palavra "sociologia" para denominar a nova ciência e proclamasse a necessidade, a conveniência e a possibilidade de aplicação dos princípios da ciência - até então aplicados apenas ao estudo dos fenômenos da natureza - ao conhecimento da sociedade, os filósofos ocuparam-se da explicação dos fenômenos sociais.

As reflexões de Platão, de Aristóteles, por exemplo, na Antiguidade, ou mesmo de Maquiavel já no Século XVI, apesar de toda a revisão, no Renascimento, das ideias tradicionais até então predominantes, são muito diversas das teorias sociológicas. A reflexão filosófica a respeito da sociedade difere da Sociologia tanto nos resultados quanto, principalmente, na maneira de alcançá-los.

Asseverar que a Sociologia é uma ciência significa, por conseguinte, antes de tudo é dizer que ela difere da Filosofia Social. Para Santos (2021) a sociologia não é fruto do simples acaso, como ciência possui princípios científicos que estuda e responde às necessidades do homem de seu tempo.

A Filosofia Social é a filosofia das ciências sociais, uma ciência pós-positivista que acredita em uma sociedade emancipada com a atual organização social sob a forma de uma tendência para o desenvolvimento, apesar dos conflitos sociais existentes. Dessa forma, a filosofia social se ocupa de três atividades: o conceito sobre uma instituição, como ela funciona e como ela se efetiva (Assal, 2017).

Por sua vez, Fernandes (1960) destaca que a Sociologia vai mais além do que o simples estudo das condições de existência social dos seres humanos. Todavia, os seres humanos é a porção mais interessante de seu objeto de estudo e aquele que instigou a aplicação do ponto de vista científico à observação e à explicação dos fenômenos sociais.

O mesmo autor ao escrever sobre o homem como objeto de indagações específicas do pensamento, tem dificuldade de identificar onde tais indagações se iniciam e quais são seus limites. No entanto, afirma que tais indagações se iniciam com a 
consciência científica no mundo moderno, a partir dos princípios e do método da ciência que procura investigar e compreender as condições da vida social dos seres humanos.

O homem ainda tem dificuldade na construção de um conceito único sobre a vida na perspectiva epistêmica, mas na consciência biológica e científica a vida é um processo dinâmico que utiliza o equilíbrio e sincronicidade da matéria, tempo e espaço, com reações e transformações químicas favoráveis ou desfavoráveis ao organismo vivo. Esse processo busca adaptabilidade do corpo vivo aos fatores intrínsecos e extrínsecos. (Nascimento-Dias, 2021). A vida social é também um processo com características próprias.

Fernandes (1960) também infere que o homem, assim como as condições de vida social dos grupos humanos, foi o principal objeto da curiosidade humana. Quando se dialoga sobre a Religião ou a Filosofia há sempre a preocupação do agente humano sobre os temas, fundamentalmente, com questões sobre a origem do homem, da vida e o destino de seus iguais. A cientificidade proporciona diferentes maneiras de expor a trajetória e determinado tipo de teoria.

Para Dias (1997, apud Weber, 1991) o ato de rezar é uma atividade contemplativa que não produz mudança social, a sociologia pode não configurar o ato como uma ação social já que não produz um ato de mudança no mundo, pode ser considerado um modo de buscar exigências profanas e manutenção de um modo de viver social (religiosidade).

Em primeiro plano, de acordo com Domingues (2001), pode-se adotar uma abordagem histórica acompanhando o surgimento da disciplina, aqui estudada, a Sociologia, seus desenvolvimentos em cada corrente e escola, os problemas surgidos em função de suas relações com a vida social e de sua atualização através de pesquisas concretas.

$\mathrm{O}$ indivíduo desde que nasce, independentemente de sua vontade, tem sua existência disciplinada por grande variedade de normas sociais, que já encontram estabelecidas em seu meio social e que lhes são impostas de forma coercitiva. Destas se sobressai, pela sua antiguidade, o costume, norma de convivência social, não estabelecida por qualquer autoridade, decorrente da repetição ininterrupta por largo tempo de um ato ou de uma conduta, garantido pela tradição e pelas sanções sociais.

A sociedade como estrutura que abriga os grupos humanos e reconhece o homem como ser social, passa a ser formalizado a partir do século XVI, por pensadores e percussores da sociologia como Rosseau, Hobbes e Locke, que tinham cada um, o conceito particular de homem. Mesmo com conceitos diferentes, os pensadores concordavam que para o homem viver em sociedade é necessário negar o egoísmo e o individualismo para alcançar segurança e reconhecimento social (Mallmann, 2018).

Um dos principais erros é conceituar a sociedade igualmente, quando na realidade cada sociedade possui sua cultua, estrato, classe, grupo, entre outros. Cada sociedade tende a denominar as ações sociais e conceder valores determinados a cada uma delas, podendo ser mais ou menos "racionais" em suas análises de categorização, assim o homem (ser social) inteligente é capaz de se sentir "destacado" em relação ao homem comum de sua sociedade. (Pereira, 1993).

Para Lucena (2010), Durkheim define o individualismo como o maior inimigo da sociedade, o individualismo destrói sua constituição e manutenção. A sociedade precisa ser mantida com uma moral coletiva expressa na divisão social do trabalho manifestada por uma solidariedade orgânica gerida por tradições, hábitos, valores e códigos morais que orientam a vida dos indivíduos em sociedade. Para Dias (1997, apud Weber, 1991) quanto mais valorizada ações sociais irracionais com origem afetiva, menos refletirá as consequências dessa ação na sociedade.

Tomazi (1993) também destaca que, de acordo com entendimento de Durkheim, a sociedade prevalece sobre o indivíduo, para esse autor, na vida em sociedade os humanos se defrontam com regras de conduta que não foram diretamente criadas por este homem, mas que existem e são aceitas na vida em sociedade, devendo ser seguidas por todos.

Para o Sociólogo Max Weber ação é um comportamento humano interno ou externo, permitido ou omitido, sempre que o(s) individuo(s) se relacione com um sentido subjetivo. A ação social acontece entre individuo(s) quando diz respeito 
sobre o comportamento de outros e orienta-se por este(s) para o seu desenvolvimento (Weber, 1921). O conceito de ação social margeia o pensamento unilateral, enquanto na relação social é a mutualidade que entra em jogo (Sell, 2016).

Intrinsicamente ligados no desenvolvimento do homem está à relação entre educação e sociedade. A educação é um processo de construção e transformação humana através da aprendizagem, oferecimento de ferramentas e habilidades para que o ser humano se relacione e conviva com outros seres humanos em sociedade (Tozoni-Reis, 2020). Outra ação social utilizada pelos gestores são as políticas públicas municipais, desenhadas para que o homem interno ou externo habite e conviva no espaço do cidadão social (Prado et al.,2020).

Para Malmann (2018), refletindo sobre o pensamento de Durkheim, coloca que a sociedade é movida de forma mecânica, repetitiva e previsível, o trabalho, o fato social e a ação social, vão direcionando as ações dos homens no meio social, nas interações sociais e de certa maneira provocando a segregação dos indivíduos.

A Sociologia cada vez mais se preocupa em repensar os pressupostos teórico-metodológicos da ciência e avaliar os alicerces que sustentam seu conhecimento sobre o mundo social, e que sustentam conceitos expressos à sociedade sobre seu entendimento científico de mundo (Alves, 2010).

Paiva e Jimenez (2010) no estudo de revisão crítica sobre a evolução do ensino da sociologia no ensino médio, as autoras identificam o discurso de educadores preocupados em formar um aluno crítico, reflexivo e cidadão de sua realidade, entretanto os educadores são superficiais em aprofundar discussões acerca da ciência sociologia.

O homem se acomoda as condições que lhe são impostas, sem criatividade e medíocre colhe as migalhas sociais que lhe são oferecidas, obedece sem questionar, vive e morre dentro das regras impostas, faz parte da massa (Malmann, 2018).

É, pois, a norma usual, repetida durante muito tempo em um espaço sociocultural, considerada obrigatória, que compreende preceitos jurídicos, morais, religiosos, regras de etiqueta, de decoro e de cerimonial (Gusmão, 1967).

\section{Considerações Finais}

Para Lenhard (1978), o ser humano recém-nascido, que se apresenta como futuro membro da sociedade e conhecedor de sua cultura que começa, por ser, apenas, um organismo, possuindo um potencial de desenvolvimento psíquico, mas não uma "personalidade", propriamente dita.

É humano em um sentido ético, como objeto de valor social e não como sujeito de vontade, conhecimento e capacidade, sendo que é a socialização por meio da educação que faz crescer nele a humanidade ativa.

A sociedade em que vive lhe impõe por costume e antiguidade, as regras, as normas e a moral, construídas e repetidas ao longo do tempo por outros seres humanos. A não adequação e a falta de respeito às tradições serão cobradas por sansões sociais.

Destarte, a socialização orienta e organiza o desenvolvimento do homem em concordância com os objetivos que a sociedade persegue. A educação possibilita também, conforme os princípios pedagógicos existentes, um meio ou situação de desenvolvimento especial e individual, de um homem ser desenvolvido pelos princípios da sociedade ou seria o fato do homem estabelecer/renovar a sociedade que habita.

O estudo vem contribuir para ampliação do debate teórico sobre a matéria de estudo da sociologia enquanto ciência social.

Sugestões para pesquisas futuras sobre a temática é pertinente, já que há uma carência de materiais publicados e disponíveis para acesso de pesquisadores, a construção de um banco de informações que ajudem na compreensão de como a sociologia contemporânea evolui a partir das ações sociais é extremamente importante.

Ademais disso, a ação social origina condições para que a personalidade do homem se forme e oriente suas atividades. Por fim, todo esse processo possibilita a socialização do indivíduo e a manutenção ou transformação da sociedade. 


\section{Referências}

Alves, P. C. (2010). A teoria sociológica contemporânea: da superdeterminação pela teoria à historicidade. Sociedade $e$ Estado, 25(1), 1531. http://dx.doi.org/10.1590/S0102-69922010000100002

Assal, J. H. (2017). A questão do argumento social-ontológico na filosofia social: a instituição social como fonte de pesquisa crítico-normativa. Revista de Filosofia, 16(2), 205-20. https://doi.org/10.31977/grirfi.v16i2.770

Denzin, N. K. \& Lincoln, I. O. (2006). Planejamento da pesquisa qualitativa: teorias e abordagens. Artmed.

Dias, W. V. (1997). Errantes em fim de século. Tempo Social, 9(2), 165-78. https://www.scielo.br/pdf/ts/v9n2/v09n2a09.pdf

Domingues, J. M. (2001). Teorias sociológicas no século XX. Civilização Brasileira.

Fernandes, F. (1960). Ensaios de sociologia geral e aplicada. Livraria Pioneira Editora.

Garcez, E. F. (2014). Weber, Schutz e a busca de "sentido" na ação social: uma análise comparativa. Em Tese, 11(1), 63-90, 2014. https://doi.org/10.5007/1806-5023.2014v11n1p63

Gil, A. C. (1999). Métodos e técnicas de pesquisa social. (5a ed.), Atlas.

Gusmão, P. D. (1967). Manual de sociologia. Forense.

Lucena, C. (2010). O pensamento educacional de Émile Durkheim. Revista HISTEDBR On-line, 10(40), 295-305. https://doi.org/10.2 0396/rho.v10i40.8639820

Mallmann, I. C. (2018). O papel do indivíduo para o desenvolvimento da sociedade. Cadernos de Ontopsicologia, Restinga Seca, 117-28. https://saberhumano.emnuvens.com.br/sh/article/view/285/306

Nascimento-Dias, B. (2021). Filosofia e história da biologia: o que é vida? RECIMA21 - Revista Científica Multidisciplinar, 2(2), 168-80. https://doi.org/10.47820/recima21.v2i2.123

Paiva, I. B.; Jimenez, S (2010) A sociologia no ensino médio: uma revisão crítica de estudos selecionados. Revista Eletrônica Arma da Crítica, Fortaleza, 2, 277-92. http://www.armadacritica.ufc.br/phocadownload/3artigo_3_especial.pdf

Pereira, J. C. (1993). Sobre o emprego do termo racional em economia e administração. Revista Administração de Empresas, 33(3), 76-83. https://doi.org/10.1590/S0034-75901993000300007

Prado, V. J.; \& Santos, J. A. G. (2020). A cidade como o espaço do habitar e a ideia da fábrica de cidades. Research, Society and Development, 9(2), 107922237. http://dx.doi.org/10.33448/rsd

Santos, A. M. (2021). Sociologia da religião - análise do impacto social da confessionalidade. RECIMA21 - Revista Científica Multidisciplinar, 4(2), e24254. https://doi.org/10.47820/recima21.v2i4.254

Sell, C. E. (2016). Max Weber e o átomo da sociologia Um individualismo metodológico moderado? Civitas, 16(2), 323-47. http://dx.doi.org/10.15448/19847289.2016.2.22167

Sell, C. E. (2001). Sociologia clássica: Durkheim, Weber e Marx. Ed. Univali.

Silva, J. A. M. \& Amorim, W. L. (2012). O pensamento sociológico de Max Weber e a educação. Revista Interdisciplinar Científica Aplicada, 6(1), 100-10. https://rica.unibes.com.br/rica/article/view/499

Tomazi, N. D. (1993). Iniciação à Sociologia. Atlas.

Tozoni-Reis, M. F. C. (2020). A contribuição da Sociologia da Educação para a compreensão da educação escolar. Texto produzido especialmente para a disciplina Sociologia da Educação do Curso de Pedagogia oferecido pela UNESP através da UNIVESP-TV. São Paulo: Universidade Estadual Paulista Júlio de Mesquita. https://fasam.edu.br/wp-content/uploads/2020/07/A-Contribui\%C3\%A7\%C3\%A3o-da-Sociologia-da-Educa\%C3\%A7\%C3\%A3p-1.pdf

Vila Nova, S. (1981). Introdução à Sociologia. Atlas.

Weber, M. (2001). A ética protestante e o espírito do capitalismo. Centauro. 